\title{
Gasless balloon laparoscopy
}

\author{
Michael Volland · Mark Lienert • Olaf Horstmann
}

Received: 27 August 2009/Accepted: 28 November 2009/Published online: 29 December 2009

(C) The Author(s) 2009. This article is published with open access at Springerlink.com

\begin{abstract}
Background The concept of balloon laparoscopy (BLSC) pursues the simplification of conventional diagnostic laparoscopy (LSC). The pneumoperitoneum is replaced by a transparent balloon, which is positioned in front of the optical system. It shall be shown that with this arrangement diagnostic LSC can be performed outside of the operating room without requiring general anesthesia.

Methods An inflatable balloon was developed for a $30 \%$ $3.5-\mathrm{mm}$ rod lens. Intra-abdominally the balloon was expanded to a diameter of $30 \mathrm{~mm}$ by air insufflation, and B-LSC was performed. Twelve patients were examined in general anesthesia before laparoscopic surgery. Twelve patients were subjected to B-LSC fully awake or with sedation (midazolam or propofol/S-ketamine) as a "second-look" procedure by way of a flexible trocar (port) left in the abdominal wall at the end of previous operation. Eight patients have been first provided with a trocar under sedation (midazolam or propofol/S-ketamine) combined with local anesthesia, and B-LSC was performed before laparoscopic surgery.

Results On a scale of $1-5$, the general impression was rated 1.9, the navigability to the different abdominal organs 2.5 , the resolution 1.5 , the stability of the system optic/ trocar 2.1, the suitability of the balloon format 1.9 , and the stability of the balloon against lateral shear forces 2.4. The degree of painfulness of the examination was rated 2.8 , the
\end{abstract}

M. Volland · M. Lienert · O. Horstmann

Department of General and Visceral Surgery, Sana-Hospital Gerresheim, Düsseldorf, Germany

M. Volland ( ()

Drakestr. 60, 12205 Berlin, Germany

e-mail: michel.volland@web.de tolerance of the port 1.4, and the degree of painfulness of trocar placement at 2.5. On a scale of 1 to 3 , the strain of the abdominal musculature was rated 1.4 and the obstruction by adhesions 1.7 .

Discussion B-LSC is technically practicable with good imaging qualities and without requiring pneumoperitoneum. It is tolerated in great extent under slight sedation and particularly well under deep sedation. The procedure is suitable for diagnostics of unclear abdominal conditions, as a second-look LSC and also as a staging LSC.

Keywords Balloon laparoscopy - Pneumoperitoneum . Unclear abdomen $\cdot$ Second look $\cdot$ Staging laparoscopy

Today's clinically established laparoscopy started on its way at the beginning of the 20th century. The idea of the pneumoperitoneum goes back to Keeling (1866-1945), who originally had the intention to stop bleeding in the abdominal cavity by means of an air tamponade $[1,2]$. In 1938 , Veress invented the well-known cannula used for the creation of a pneumoperitoneum. This cannula was originally conceived for the purpose of creating a therapeutical pneumothorax in the treatment of tuberculosis [3]. Further technical achievements on the pathway of laparoscopy were the automatic insufflators (1966), as well as the introduction of video laparoscopy with image transfer to a monitor (1982). The first milestones in laparoscopic visceral surgery were set with the first laparoscopic appendectomy by Semm in 1982, as well as the first laparoscopic cholecystectomy by Mühe in 1985 [3, 4].

By now, laparoscopic operation techniques performed on the gastrointestinal tract have superseded conventional laparotomy methods at numerous indications. The standard for diagnostic purposes is still laparoscopy with a $10-\mathrm{mm}$ 
optical system under general anesthesia using pneumoperitoneum.

The side effects of the pneumoperitoneum were analyzed en suite with the increasing propagation of laparoscopy. Specific pathophysiological processes occurring with the $\mathrm{CO}_{2}$ pneumoperitoneum can be related to the formation of a metabolic acidosis by $\mathrm{CO}_{2}$ absorption, in conjunction with increased postoperative pain, particularly in the shoulder region, as well as gas embolism. Every form of pneumoperitoneum can lead to hypoventilation and a reduction of the cardiac output caused by the increased intraabdominal pressure [5-10]. These aspects are not to be neglected, particularly in case of older patients with an increased cardiovascular risk profile, and in case of obese patients who already have an increased intra-abdominal pressure $[11,12]$.

The $\mathrm{N}_{2} \mathrm{O}$ pneumoperitoneum is preferred in gastroenterological minilaparoscopy to avoid the postoperative pain caused by the application of $\mathrm{CO}_{2}$, because $\mathrm{N}_{2} \mathrm{O}$ has an analgesic effect [13]. The use of ambient air in the creation of a pneumoperitoneum is problematic, because it leads to inferior viewing, increased wound infections, and increased postoperative pain [14].

The method of gasless balloon laparoscopy (balloon LSC) described here has the intention to technically and logistically simplify diagnostic laparoscopy outside of the operating room. The risks connected with the pneumoperitoneum and with general anesthesia shall be avoided at the same time.

The starting point for the development of balloon LSC was the search for an improved method for the diagnosis of unclear abdominal complaints. Conservative waiting or early elective explorative laparoscopy is the alternative, for which there are no definite and clear paths of treatment, and the consequences of which can be far-reaching. A quick look into the abdominal cavity would frequently be desirable; however, but the complexity of diagnostic laparoscopy under surgical conditions, together with the risks of general anesthesia, do not seem justified. Other imaging methods, such as ultrasound or computer tomography, do not permit reliable assessments, specifically in the differential diagnoses of acute appendicitis or gut ischemia. In unclear situations, we have diagnostic uncertainties that unnecessarily increase the risk for the patient and the treating team as well. On the other hand, there are numerous unnecessary appendectomies still performed in the context of diagnostic laparoscopy due to diagnostic uncertainty.

Aside from the situation of an "unclear abdomen," there also is a similar diagnostic gap in the postoperative course after surgical interventions concerning the abdomen. This is confirmed by a study that surgeons lack predictive accuracy for anastomotic leakage in gastrointestinal surgery [15]. Leakages could be identified at an early stage by balloon LSC, and important therapeutical decisions could be initiated promptly.

Staging laparoscopy for the diagnosis of the extent of tumors and peritoneal carcinomatosis, including biopsy, also could be simplified with balloon LSC.

\section{Materials and methods}

A balloon system was developed for the $30^{\circ} / 3.5-\mathrm{mm}$ endoscope with a length of $300 \mathrm{~mm}$ (Wolf, Knittlingen, Germany). This system consisted of a stabilizing metal sleeve, at the end of which a foldable, transparent balloon was attached; the other end was provided with a sealing closure device. After creation of a minimally invasive access to the abdominal cavity, the balloon system was introduced with the aid of a guidance rod. The endoscope was introduced into the balloon system after retraction of the guidance rod, then the system was sealed by the closure device, and the balloon was expanded to a diameter of $30 \mathrm{~mm}$ by external inflation with $30 \mathrm{ml}$ of air. The image transfer was performed by means of a conventional laparoscopy camera, which was connected to the endoscope. The intra-abdominal organs were accessed and depicted by specific external guidance of the camera (Figs. 1 and 2).

The study was performed in accordance with the German Medical Device Directive (MDD) with the consent of

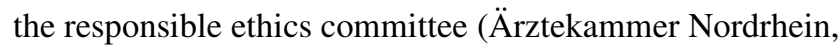
Germany) in correspondence with the Declaration of Helsinki (1964). After obtaining the written consent to participate in the study, 32 patients (18 women; mean age,

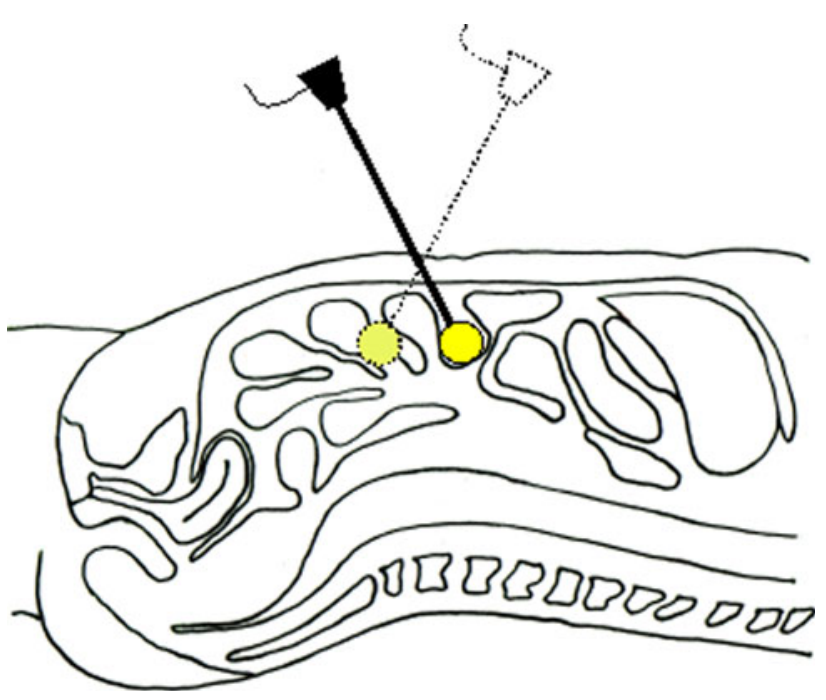

Fig. 1 Principle of balloon LSC. The transparent balloon in front of the endoscope is intra-abdominally filled with air and is guided through the abdominal cavity together with the optical system. Pneumoperitoneum is not required 
Fig. 2 Balloon system with introduced laparoscope $(3.5 \mathrm{~mm})$

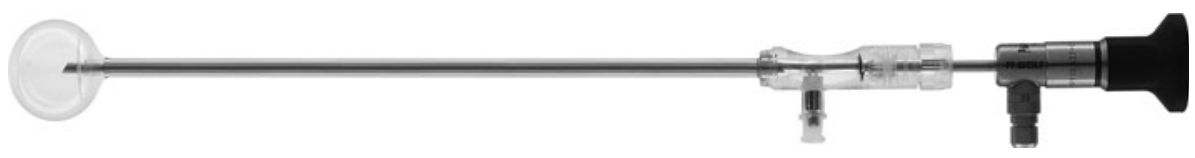

60.1 ( \pm 16.3 ) years) were included. All patients had been fasting preoperatively. Exclusion criteria were age younger than 18 years, the taking of anticoagulants or coagulation disorders, as well as pregnancy and nursing period. Fifty percent of the patients had previously undergone abdominal surgery. All examinations carried out in the context of the study were performed as supplementary measures in addition to the indicated operations.

Two study groups with respectively 12 patients were formed, as well as one study group with 8 patients (Tables 1, 2). In group 1 (8 women; mean age, 52.4 (range, 25-72) years; body mass index (BMI), 27.3), balloon LSC was performed on 11 patients under general anesthesia before the beginning of a surgical intervention (laparoscopic cholecystectomy $(n=5)$, laparoscopic sigmoidectomy $(n=3)$, laparoscopic appendectomy $(n=2)$, conventional gastrectomy $(n=1))$. An advanced peritoneal carcinomatosis was established by balloon LSC for one patient of group 1, just as it was confirmed by following conventional laparoscopy, so that the planned operation was not performed. The required minilaparotomy was partly performed infraumbilical $(n=9)$ and partly supraumbilical $(n=3)$.

In the second group, balloon LSC was intended as a second-look procedure performed on 12 patients (6 women; mean age, 66.6 (range, 41-80) years; BMI, 27.0) after visceral surgical intervention. Balloon LSC was performed on the first postoperative $(n=11)$ or second postoperative $(n=1)$ day by flexible trocar (port), which had been positioned in the abdominal wall during the course of the primary

Table 1 Overview of the three groups

\begin{tabular}{cl}
\hline Group & Balloon LSC in general anesthesia $(n=12)$ \\
1 & Before laparoscopic operations \\
& Access by mini-laparotomy \\
Group & Second-look balloon LSC without general anesthesia \\
2 & $(n=12)$ \\
& Without sedation $(n=5)$, midazolam $(n=5)$, \\
& propofol + S-ketamine $(n=2)$ \\
& Examination on first $(n=11)$ or second $(n=1)$ \\
& postoperative day \\
& Access via port \\
Group & Trocar introduction and balloon LSC without general \\
3 & anesthesia $(n=8)$ \\
& Midazolam $(n=2)$, propofol + S-ketamine $(n=6)$ \\
& Before laparoscopic operations \\
& Access with optical trocar
\end{tabular}

surgery. The second-look examination was performed in the intensive care unit, the postanesthesia care unit, or an intervention room of the outpatient department under monitoring of ECG, blood pressure, and $\mathrm{O}_{2}$ saturation. Five probands underwent examination without sedation and five probands received slight sedation (max. $5 \mathrm{mg}$ of midazolam) as well as analgetics (via peridural catheter or opioids intravenous) and were responsive during the examination. Two patients received deep sedation with propofol (40-60 mg) and Sketamine (10-15 mg). The primary operations involved were laparoscopic cholecystectomies $(n=2)$, laparoscopic sigmoidectomy ( $n=3$ ), conventional right hemicolectomy $(n=2)$, conventional sigmoidectomy $(n=1)$, choledochojejunostomy $(n=1)$, partial gastrectomy $(n=1)$, subtotal colectomy ( $n=1)$ with partial gastrectomy, as well as a laparoscopic fundoplication $(n=1)$.

In the third group (4 women; mean age, 62.8 (range, 4484) years; BMI, 26.6), eight patients were examined by balloon LSC without general anesthesia before the beginning of laparoscopic operations (laparoscopic cholecystectomy $(n=6)$, laparoscopic appendectomy $(n=2))$.

The access was performed by a special optical trocar conceived for the 3.5-mm endoscope, which was provided with transparent and atraumatic tip geometry for trocar placement under viewing.

All eight patients received local anesthesia (mepivacaine $1 \%$ ) in the area of the incision. First, small depots were administered subcutaneously for skin analgesia (1$2 \mathrm{ml})$, as well as epifascially $(0.5 \mathrm{ml})$. After perforation of the fascia with the cannula, the bulk quantity of local anesthetic was deposited in the preperitoneal space below the fascia (approximately 5-8 $\mathrm{ml}$ ).

Aside from local anesthesia, two patients received slight sedation with midazolam $(3-5 \mathrm{mg}$ ) and were responsive during the examination; six patients were provided with deep sedation using propofol (60-160 mg) and S-ketamine (15-30 mg).

The following technical parameters and patient tolerance were evaluated by the surgeon or patients by means of an assessment sheet:

1. Visualization/general impression

2. Navigability to the various abdominal organs

3. Resolution

4. Stability of the combined systems optical system/ trocar

5. Suitability of the balloon format

6. Stability of the balloon against lateral shear forces

7. Painfulness of the examination maneuver 
Table 2 Evaluation of the 11 parameters in the respective groups

\begin{tabular}{llll}
\hline Parameter & Group & Results & Scale \\
\hline 1. Visualization/general impression & $1-3$ & $1.9( \pm 0.7)$ & $1-5(1=$ very good, 5= very bad) \\
2. Navigability to the different abdominal organs & $1-3$ & $2.5( \pm 0.8)$ & $1-5$ (s. 1.) \\
3. Resolution & $1-3$ & $1.5( \pm 0.6)$ & $1-5$ (s. 1.) \\
4. Stability of the combined system optic/trocar & $1-3$ & $2.1( \pm 0.6)$ & $1-5$ (s. 1.) \\
5. Suitability of the balloon format & $1-3$ & $1.9( \pm 0.4)$ & $1-5$ (s. 1.) \\
6. Stability of the balloon against lateral shear forces & $1-3$ & $2.4( \pm 0.8)$ & $1-5$ (s. 1.) \\
7. Painfulness of the examination maneuver & $2+3$ & $2.8( \pm 1.1)$ & $1-5(1=$ no pain, 5= severe pain) \\
8. Patient tolerance of the port & 2 & $1.4( \pm 0.7)$ & $1-5$ (s. 7.) \\
9. Painfulness of trocar placement & 3 & $2.5( \pm 0.9)$ & $1-5$ (s. 7.) \\
10. Strain of the abdominal musculature & $2+3$ & $1.4( \pm 0.5)$ & $1-3(1=$ no occurrence, 3= extreme occurrence) \\
11. Obstruction by adhesions & $1-3$ & $1.7( \pm 0.8)$ & $1-3$ (s. 10.) \\
\hline
\end{tabular}

8. Patient tolerance of the port

9. Painfulness of trocar placement

10. Strain of the abdominal musculature

11. Obstruction of the examination by adhesions

\section{Results}

Of the 11 investigated parameters (Figs. 3, 4, 5), the first 6 parameters referring to the technical qualities of the balloon system were evaluated in all 3 groups $(n=32)$. The parameters referring to patient tolerance of the method (parameters 7-9) as well as parameter 10 (strain of the abdominal musculature) were assessed in the groups 2 and 3 (sedated patients, $n=20$ ). The rating of parameter 11 (obstruction by adhesions) was performed in all three groups $(n=32)$. Parameters $1-9$ were classified on a scale of $1-5(1=$ very good, $5=$ very bad $/ 1=$ no pain, $5=$ severe pain). Parameters 10 and 11 were classified on a scale of $1-3 \quad(1=$ no occurrence, $3=$ extreme occurrence).

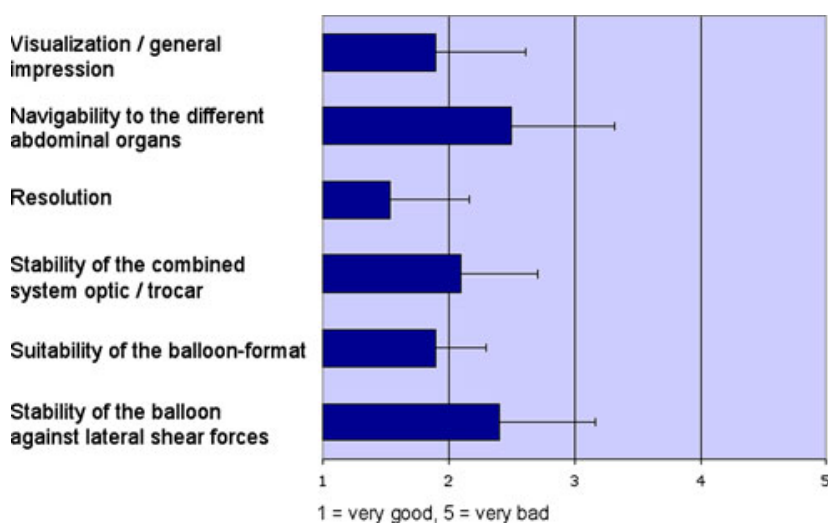

Fig. 3 Examination technique $(n=32)$

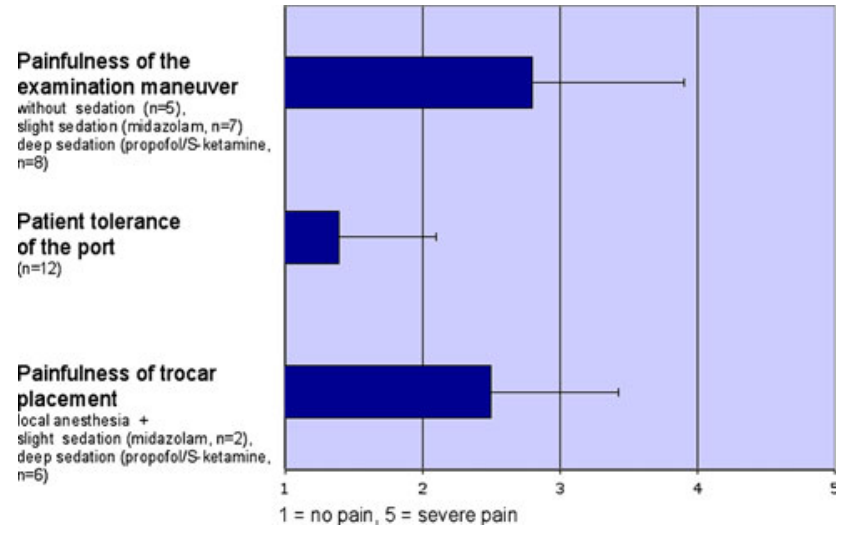

Fig. 4 Patient tolerance

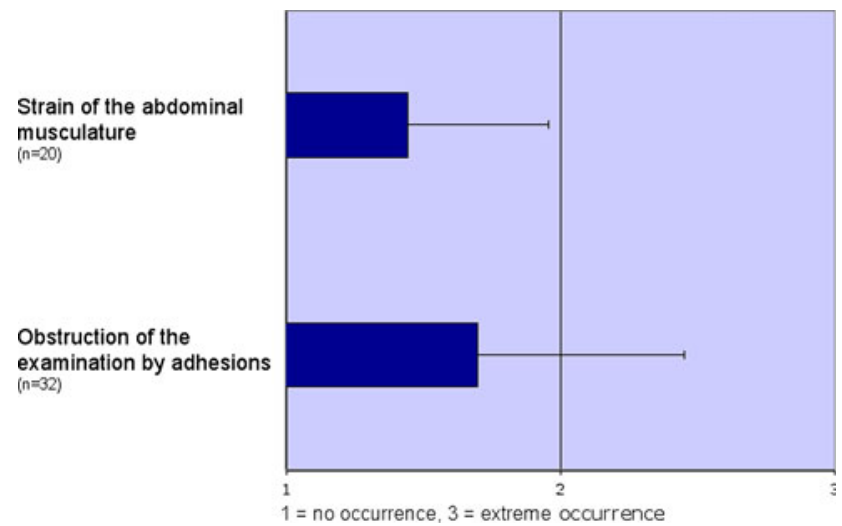

Fig. 5 Additional parameters

Complications did not appear in connection with balloon LSC. Vasovagal reactions were not detected at any examination.

In group 2 (second look), two of ten patients stated that they felt stronger pain at the beginning, therefore both of their examinations were aborted. The two last examinations in group 2 were therefore performed under deep sedation 
with propofol and S-ketamine, and they progressed without problems. In group 3, the first two patients under slight sedation (midazolam) expressed that they partly felt increased pain during the examination; therefore, the following examinations in group 3 were conducted under deep sedation (propofol/S-ketamine) (Figs. 3, 4, 5, 6, 7, 8, 9).

\section{Discussion}

Laparoscopic operation techniques are regarded as minimally invasive compared with operations that use laparotomy as an access procedure. Classic laparoscopy for purely

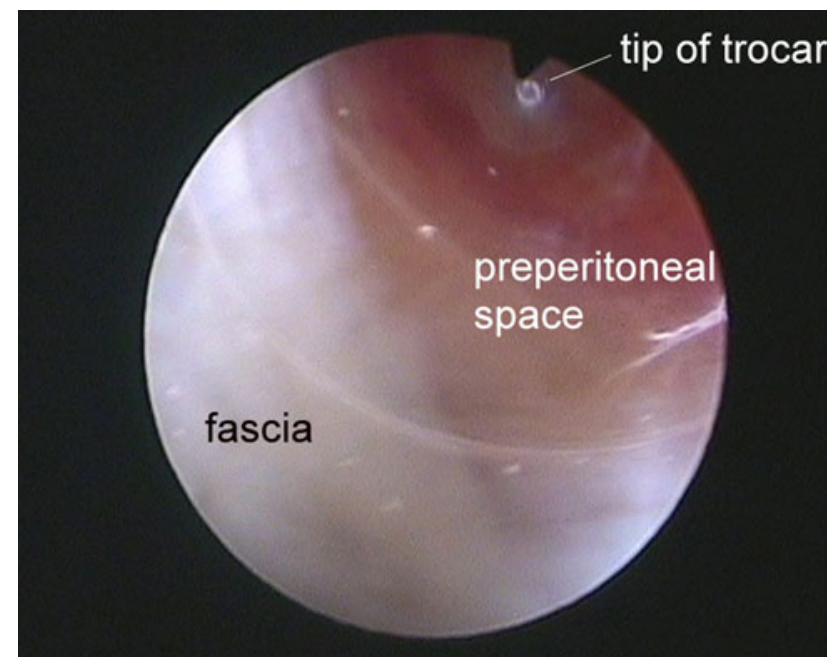

Fig. 6 Introduction of the optical trocar via an infraumbilical incision (screen shot)

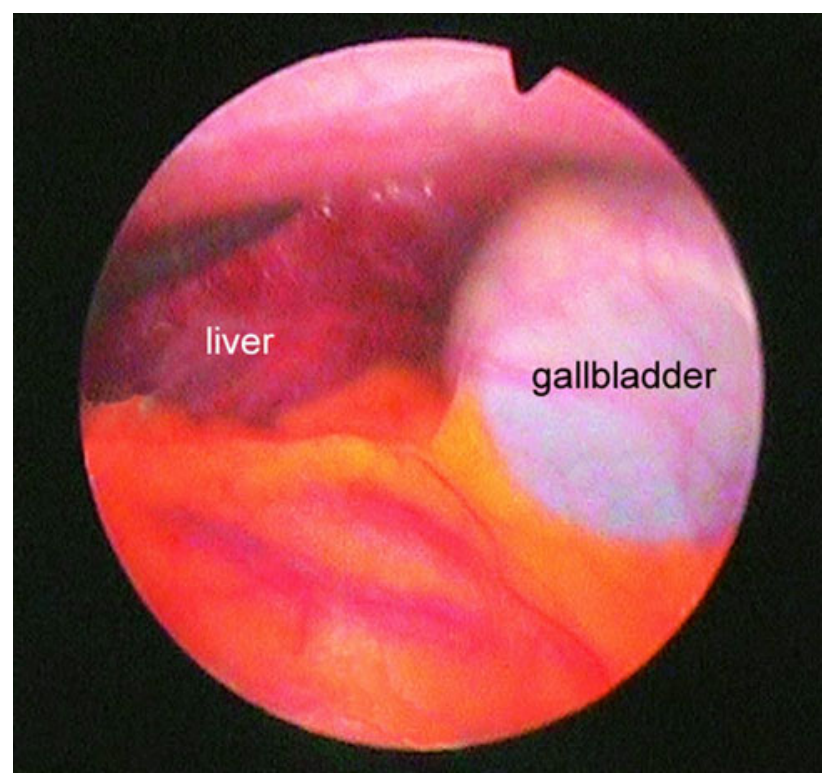

Fig. 7 Liver and gallbladder (screen shot)

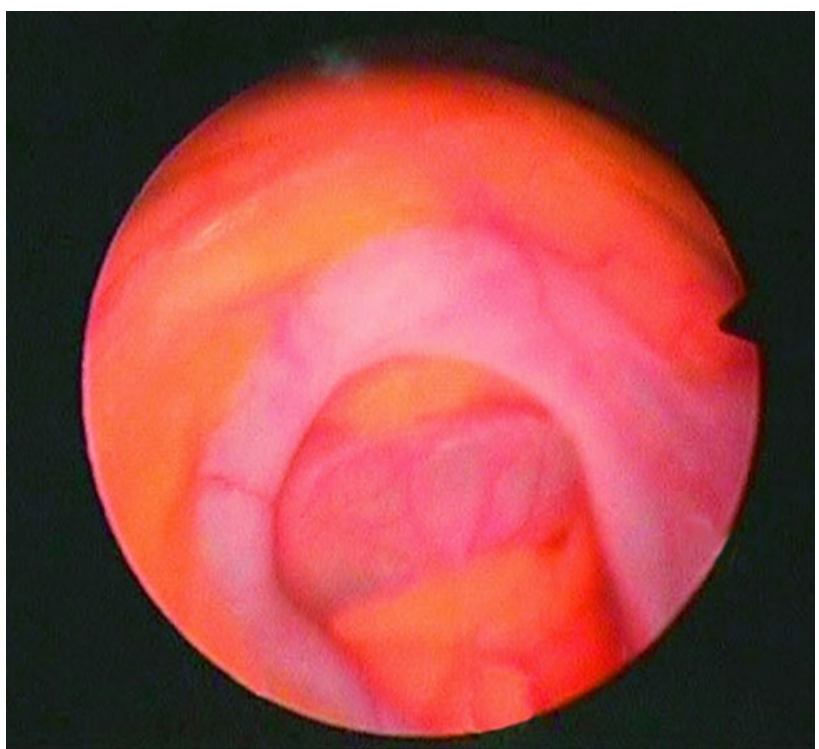

Fig. 8 Appendix (screen shot)

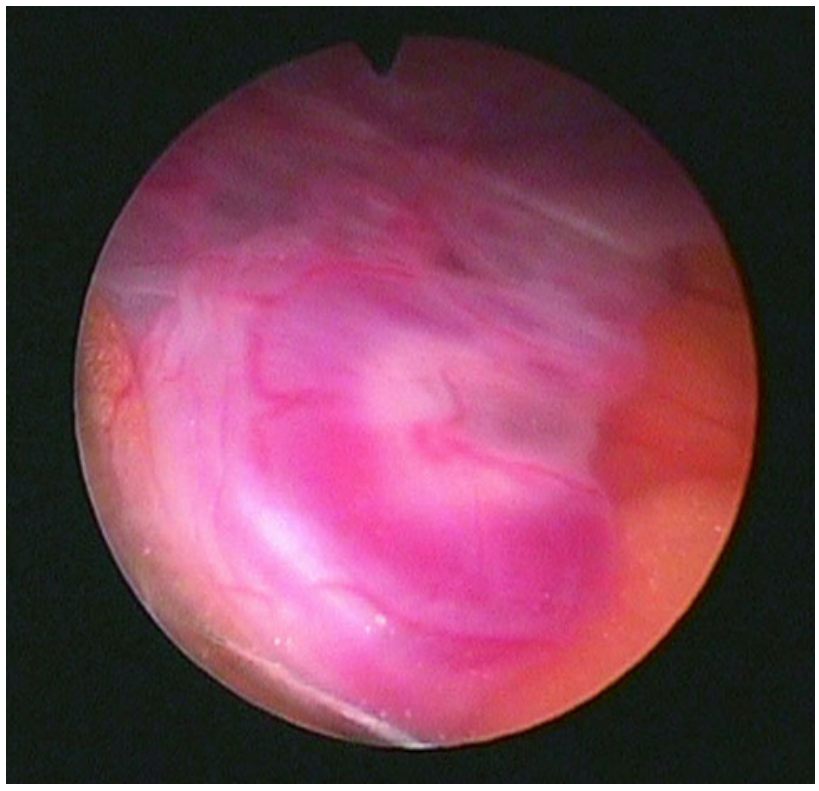

Fig. 9 Oviduct (screen shot)

diagnostic purposes is inflicted with risks and it is technically complex due to the pneumoperitoneum and general anesthesia compared with noninvasive imaging methods.

Minilaparoscopy, which can be performed under deep sedation, has found wide-spread propagation in gastroenterology with the purpose of avoiding general anesthesia. Optical systems with diameters $<3 \mathrm{~mm}$ are used, but the creation of a pneumoperitoneum is required [16-18]. The diagnosis of unclear hepatic diseases is of great interest from the viewpoint of gastroenterology. The macroscopic results of the liver constitute an important supplement, in addition to the pathological specimen [19-21]. 
Various systems that do not require a pneumoperitoneum have been developed for laparoscopic surgery. With the aid of special retractors introduced intra-abdominally by way of minilaparotomy, the abdominal wall can be lifted. A visual space in analogy to the pneumoperitoneum is created under the abdominal wall in this manner [22-25]. However, abdominal wall lifting systems do have disadvantages with regard to practicability and overview [2628]. The difference in postoperative pain perceived in case of $\mathrm{CO}_{2}$ gas laparoscopy compared with gasless lift laparoscopy is only insignificant [29]. Deep sedation is not sufficient, because the abdominal wall lifting systems are designed for abdominal interventions.

The balloon LSC technique introduced in this study renders the creation of a pneumoperitoneum as not required, and it can be performed without general anesthesia outside of the operating room. It could be shown by the study that this method is technically practicable and is tolerated well by the patients under sedation.

The 3.5-mm optical system permits an optimal illumination of the field of vision (Figs. 7, 8, 9). The balloon in front of the lens prevents disturbing tissue contact, as well as the condensation of vapor on the optical system. Retraction and cleaning of the optical system, a frequent and disturbing necessity in conventional laparoscopy, becomes obsolete. Together with the magnifying effect of the camera, the system provides high-resolution close-ups with constant distance to the object. Thus, examinations between the intra-abdominal organs are possible without additional instruments.

The metal shaft of the balloon system guarantees mechanical protection of the optical system against buckling or creasing. The range of the optical system is correctly dimensioned with $300 \mathrm{~mm}$, which permits access of all intra-abdominal organs in cases of moderately adipose patients (8 patients with BMI $>30$ ). However, the space available for movement is limited in cases of massive obesity (1 patient with a BMI of 40.1) due to preperitoneal soft tissue inhibition. A compromise between maneuverability and sufficient overview was found with a balloon format of approximately $30 \mathrm{~mm}$ in diameter. Balloon systems used in totally extraperitoneal hernia surgery (TEP) have considerably greater diameters and are unsuitable for maneuvering between the abdominal organs. Balloon diameters $<30 \mathrm{~mm}$ would not provide a sufficient overview.

It could be shown with regard to patient tolerance that balloon LSC is largely tolerated by patients who are slightly sedated (midazolam) and responsive. However, deep sedation with propofol $(60-160 \mathrm{mg})$ and S-ketamine $(5-30 \mathrm{mg})$ has proven to be generally effective to avoid pain.
A great inter- and intra-individual variability of pain sensation has been noticed in the second-look examinations. Pain could be primarily provoked when maneuvering the balloon system intra-abdominally in the area of the incision in the abdominal wall, as well as by a stretch stimulus applied to the peritoneum. The moving of the balloon system outside of the primary surgical area was, upon direct questioning, at times hardly perceived and at times not noticed at all.

Respiratory depression is not expected considering the relatively low dosages of propofol and S-ketamine referred to. Therefore, the presence of an anesthetist is not required if the patient has fasted and if corresponding monitoring (ECG, blood pressure, $\mathrm{O}_{2}$ saturation) is ensured.

The presence of the port in the time between the primary operation and the second-look (group 2) was not considered as bothersome or annoying by the patients. The second-look examination was, however, normally performed on the first postoperative day, so that the observation period was kept relatively short. Balloon LSC appears to be particularly suitable for the early elective control of critical anastomosis with intraoperatively doubtful perfusion. Balloon LSC also is advised without delay to exclude manifest anastomosis insufficiency upon clinical suspicion of such (mostly after the third postoperative day), before inflammatory adhesions obstruct the maneuvering of the balloon system.

Balloon LSC has interdisciplinary ranges of application. In the adjacent disciplines of gastroenterology, gynecology, and urology, it could enlarge the diagnostic spectrum as it has in intensive care medicine [30-32]. The utilization of balloon LSC also is conceivable in the fields of heart and blood vessel surgery (postoperative control of bowel perfusion), video-assisted thorax surgery (VATS), senology (revision of breast implants), and in neonatology (diagnostics of enterocolitis necroticans).

It could be shown by this study that balloon LSC constitutes a safe and simple method for short-term diagnostics of unclear abdominal complaints, for staging laparoscopy, and for postoperative control. More advanced and further developed balloon systems for the extraction of biopsies are presently in the trial-testing phase. Future investigations will show the transferability of balloon LSC to flexible endoscopes, for imaging of spaces that are difficult to access.

Acknowledgments Abstracts about this study also were published in: Volland M, Lienert M, Horstmann O (2008) Die gaslose BallonLaparoskopie - ein neues Verfahren zur abdominellen Diagnostik. Z Gastroenterol 46:923-1093, poster presentation; Volland M, Lienert M, Horstmann O (2009) Gasless balloon laparoscopy: a new method in abdominal diagnostics. Surg Endosc 23:S141-S145, oral presentation. 
Disclosures The authors would like to thank the manufacturer of the instruments (PAJUNK ${ }^{\circledR}$ Medi-zintechnologie GmbH, Karl-HallStraße 1, 78187 Geisingen, Germany) for the engineering and the generous supply of the equipments.

Open Access This article is distributed under the terms of the Creative Commons Attribution Noncommercial License which permits any noncommercial use, distribution, and reproduction in any medium, provided the original author(s) and source are credited.

\section{References}

1. Litynski G, Schaeff B, Paolucci V (1996) From pneumoperitoneum to coelioscopy: Georg Kelling (1866-1945)—the pioneer of laparoscopy. Chirurg 67(3):283-287

2. Schollmeyer M, Schollmeyer Th (2001) Georg Kelling und die sächsischen Wurzeln der Laparoskopie-100 Jahre Laparoskopie (1901-2001). Ärzteblatt Sachsen 522-524

3. Litynski GS (1996) Highlights in the history of laparoscopy. Bernert Verlag, Frankfurt/Main

4. Reynolds W Jr (2001) The first laparoscopic cholecystectomy. JSLS 5(1):89-94

5. Wittgen CM, Andrus CH, Fitzgerald SD, Baudenstel LJ, Dahms R, Kaminski DL (1991) Analysis of hemodynamic and ventilatory effects of laparoscopic cholecystectomy. Arch Surg 126:97101

6. McLaughlin JG, Bonnel BW, Scheeres DE, Dean RJ (1992) The adverse hemodynamic effects related to laparoscopic cholecystectomy. Anesthesiology 77:70-77

7. Sharma KC, Kabinoff G, Ducheine Y, Tierney J, Brandstetter RD (1997) Laparoscopic surgery and its potential for medical complications. Heart Lung 26:52-64 quiz 65-67

8. Nesek-Adam V, Mrsi V, Smiljani A, Oberhofer D, Grizelj-Stojci E (2007) Pathophysiologic effects of CO2-pneumoperitoneum in laparoscopic surgery. Acta Med Croatica 61(2):165-170

9. Gutt CN, Oniu T, Mehrabi A, Schemmer P, Kashfi A, Kraus T, Büchler MW (2004) Circulatory and respiratory complications of carbon dioxide insufflation. Dig Surg 21(2):95-105 Epub 2004 Feb 27

10. Bickel A, Loberant N, Bersudsky M, Goldfeld M, Ivry S, Herskovits M, Eitan A (2007) Overcoming reduced hepatic and renal perfusion caused by positive-pressure pneumoperitoneum. Arch Surg 142(2):119-124 discussion 125

11. Nguyen NT, Wolfe BM (2005) The physiologic effects of pneumoperitoneum in the morbidly obese. Ann Surg 241(2):219226

12. El-Dawlatly AA (2007) Hemodynamic profile during laparoscopic cholecystectomy versus laparoscopic bariatric surgery: the impact of morbid obesity. Middle East J Anesthesiol 19(1):51-60

13. Tsereteli Z, Terry ML, Bowers SP, Spivak H, Archer SB, Galloway KD, Hunter JG (2002) Prospective randomized clinical trial comparing nitrous oxide and carbon dioxide pneumoperitoneum for laparoscopic surgery. J Am Coll Surg 195(2):173-179 discussion 179-180

14. Ikechebelu JI, Obi RA, Udigwe GO, Joe-Ikechebelu NN (2005) Comparison of carbon dioxide and room air pneumoperitoneum for day-case diagnostic laparoscopy. J Obstet Gynaecol 25(2):172-173

15. Karliczek A, Harlaar NJ, Zeebregts CJ, Wiggers T, Baas PC, van Dam GM (2009) Surgeons lack predictive accuracy for anastomotic leakage in gastrointestinal surgery. Int J Colorectal Dis 24(5):569-576 Epub 2009 Feb 17

16. Helmreich-Becker I, Meyer zum Büschenfelde KH, Lohse AW (1998) Safety and feasibility of a new minimally invasive diagnostic laparoscopy technique. Endoscopy 30:756-762

17. Denzer U, Lohse A (2006) Internistische Mini-Laparoskopie: Technik, Indikationen, Kontraindikationen und Qualitätskontrolle. www.minilap.de. Updated 7 May 2006

18. Denzer U, Hoffmann S, Helmreich-Becker I, Kauczor HU, Thelen M, Kanzler S, Galle PR, Lohse AW (2004) Minilaparoscopy in the diagnosis of peritoneal tumor spread: prospective controlled comparison with computed tomography. Surg Endosc 18(7):1067-1070 Epub 2004 May 27

19. Poniachik J, Bernstein DE, Reddy R, Jeffers LJ, Coelho-Little ME, Civantos F et al (1996) The role of laparoscopy in the diagnosis of cirrhosis. Gastroint Endosc 43:568-571

20. Helmreich-Becker I, Schirmacher P, Denzer U, Hensel A, Meyer zum Büschenfelde KH, Lohse AW (2003) Minilaparoscopy in the diagnosis of cirrhosis: superiority in patients with Child-Pugh A and macronodular disease. Endoscopy 35(1):55-60

21. Denzer U, Arnoldy A, Kanzler S, Galle PR, Dienes HP, Lohse AW (2007) Prospective randomized comparison of minilaparoscopy and percutaneous liver biopsy: diagnosis of cirrhosis and complications. J Clin Gastroenterol 41(1):103-110

22. Kruschinski D, Homburg S, Langde S, Kapur A (2008) Dermoid tumors of the ovary: evaluation of the gasless lift-laparoscopic approach. Surg Technol Int 17:203-207

23. Akira S, Abe T, Igarashi K, Nishi Y, Kurose K, Watanabe M, Takeshita T (2005) Gasless laparoscopic surgery using a new intra-abdominal fan retractor system: an experience of 500 cases. J Nippon Med Sch 72(4):213-216

24. Hyodo M, Sekiguchi C, Ohdaira T, Chiba H, Ohtsuka S, Nagai H (2004) Gasless laparoscopy-assisted colon surgery utilizing minilaparotomy and a subcutaneous abdominal wall lift system. Hepatogastroenterology 51(58):1011-1014

25. Egawa H, Morita M, Yamaguchi S, Nagao M, Iwasaki T, Hamaguchi S, Kitajima T, Minami J (2006) Comparison between intraperitoneal $\mathrm{CO} 2$ insufflation and abdominal wall lift on QT dispersion and rate-corrected QT dispersion during laparoscopic cholecystectomy. Surg Laparosc Endosc Percutan Tech 16(2):7881

26. Johnson PL, Sibert KS (1997) Laparoscopy. Gasless vs. $\mathrm{CO}_{2}$ pneumoperitoneum. Reprod Med 42(5):255-259

27. Goldberg JM, Maurer WG (1997) A randomized comparison of gasless laparoscopy and CO2 pneumoperitoneum. Obstet Gynecol 90(3):416-420

28. Alijani A, Hanna GB, Cuschieri A (2004) Abdominal wall lift versus positive-pressure capnoperitoneum for laparoscopic cholecystectomy. Ann Surg 239(3):388-394

29. Guido RS, Brooks K, McKenzie R, Gruss J, Krohn MA (1998) A randomized, prospective comparison of pain after gasless laparoscopy and traditional laparoscopy. J Am Assoc Gynecol Laparosc 5(2):149-153

30. Jaramillo EJ, Trevino JM, Berghoff KR, Franklin ME Jr (2006) Bedside diagnostic laparoscopy in the intensive care unit: a 13year experience. JSLS 10(2):155-159

31. Pecoraro AP, Cacchione RN, Sayad P, Williams ME, Ferzli GS (2001) The routine use of diagnostic laparoscopy in the intensive care unit. Surg Endosc 15(7):638-641 Epub 2001 May 14

32. Gagne DJ, Malay MB, Hogle NJ, Fowler DL (2002) Bedside diagnostic minilaparoscopy in the intensive care patient. Surgery 131(5):491-496 